\title{
Second Generation DES: Better Option in Treatment ISR Hristova $\mathbf{N}^{*}, \mathbf{T}$ Atzev \\ University Hospital "St Ekaterina", Clinic of Cardiology and Cardiosurgery, 52 A Bul. Pencho Slavejkov, 1431 Sofia, Bulgaria
}

\begin{abstract}
The development of an effective strategy for treatment of in-stent restenosis after BMS placement has been found to be extremely complicated. The therapeutic purpose for many patients is achieved with the implantation of DES - an option which is still not investigated and studied enough. 152 patients with implanted drug-eluting stents (different generations) for severe in-stent restenosis were followed up for a period of 9 years in the department of cardiology of University Hospital "St. Ekaterina". Patients were divided into two groups - 131 patients with implanted first generation DES, and 21 patients - with second generation DES. Patients were followed up clinically (reversed angina, MI, emergency CABG, death), EchoCG and/or ECG stress test. Patients with angina pectoris and/or decreased LV function were assessed by conventional or CT angiography. Serious complications were not observed. 9 patients were with significant in-stent proliferation, and the others were with patent stents.

Implementation of DES for treatment of in-stent restenosis is an established method, because of its reliability and safety with low percentage of complications.
\end{abstract}

Keywords: In-stent restenosis; Drug-eluting stent

\section{Introduction}

In-stent restenosis (ISR), lack of treatment for chronic total occlusions and diffuse coronary artery disease in diabetics are fundamental challenges in interventional cardiology. Restenosis after bare metal stent (BMS) implantation has been considered to be the most significant problem in coronary interventional treatment [1]. Proven risk factors are: small diameter of the vessel, previous restenosis, long stented segments, ostial lesions, and diabetes mellitus [2]. Several techniques and strategies for the treatment of ISR have been used historically - atherectomy, cutting baloon, brachytherapy, POBA, DES, CABG $[3,4]$. Each one demonstrated some success but the best approach remains unsettled [5]. Drug - eluting stents (DES) have dramatically reduced the rates of restenosis and target lesion revascularization compared with BMS [6,7]. 12 years after the first DES implantation the "perfect stent" is not found yet, but the variety of stents and cumulated experience, especially after the introduction of the first generation DES, approved them as a safe and reliable method for treating of in-stent restenosis in patients with different risk profile. This review will focus on the treatment of patients with ISR with different generation DES implantation.

\section{Aim}

To evaluate and analyse early and late results in patients with instent restenosis treated with different generation's drug-eluting stent for a period of 2 years.

\section{Methods}

This was a retrospective study of 152 patients with implanted drugeluting stents (different generations) for significant in-stent restenosis, who were followed up for a period of 9 years - from January 2004 up to December 2012 in the department of cardiology of University Hospital "St. Ekaterina".

Patients were divided into two groups:

\begin{tabular}{|c|c|c|}
\hline Follow up & I group - 131pts & II group - 21pts \\
\hline Coronary angiography & 41 out of $131 / 31 \% /$ & 1 out of $21 / 5 \% /$ \\
\hline \multicolumn{2}{|c|}{ Table 1: Angiographic follow up. }
\end{tabular}

I group - 131 patients with impalnted first generation DES - sirolimus- eluting stent (SES), paclitaxel - eluting stent (PES), tacrolimus - eluting stent

II group - 21 patients with implanted second generation DES everolimus - eluting stent (EES), biolimus A - eluting stent (BES).

Medical therapy after the procedure ( minimum 1 year) included dual antiplatelet therapy, statin and standard antianginal agents.

All of the patients were followed up for early or late manifestation of reversed angina, $\mathrm{MI}$, emergency CABG, death, repeat revascularization, LV function assessment. Physical examination, echocardiography and/ or ECG stress test (according to indications and contraindications) were performed for each patient. Patients with angina pectoris and/or decreased LV function were checked by conventional angiography or CT angiography (Table 1).

Patients were between 34 and 87 years old. $80 \%$ from the studied population were male and $20 \%$ - female (Figure 1).

The main clinical characteristics of each patient are summarized in Table 2. In both groups prevail patients with stable angina with no severe heart failure. The percentage of patients with chronic renal insufficiency is relatively low (none in group II). There are no patients after surgical revascularization in the second group.

Highest is the frequency of arterial hypertension and dyslipidemia, followed by diabetes mellitus and smoking concerning the risk factors for ischemic heart disease (Table 3).

*Corresponding author: Nadezhda Hristova, Cardiology clinic, University hospital" St. Ekaterina", bul. Pencho Slaveikov 52 A, Sofia, Bulgaria, Tel: +359 895418911; +35929549057; E-Mail: nainadia@yahoo.com

Received March 17, 2014; Accepted April 28, 2014; Published April 30, 2014

Citation: Hristova N, Trendafilova D, Jorgova J, Atzev B (2014) Second Generation DES: Better Option in Treatment ISR. J Vasc Med Surg 2: 133. doi: 10.4172/23296925.1000133

Copyright: (c) 2014 Hristova N, et al. This is an open-access article distributed under the terms of the Creative Commons Attribution License, which permits unrestricted use, distribution, and reproduction in any medium, provided the original author and source are credited. 


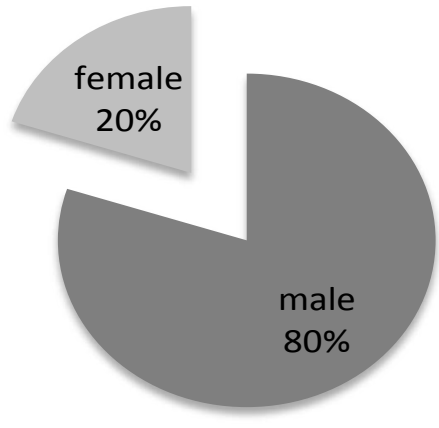

Figure 1: Demographic characteristics.

\begin{tabular}{|c|c|c|}
\hline & $\begin{array}{l}\text { I group - I generation } \\
\text { DES - } 131 \text { pts }\end{array}$ & $\begin{array}{c}\text { II group - II generation } \\
\text { DES - 21pts }\end{array}$ \\
\hline Stable angina & 87 out of $131 / 66 \% /$ & 8 out of $21 / 38 \% /$ \\
\hline Unstable angina & 42 out of $131 / 32 \% /$ & 9 out of $21 / 29 \% /$ \\
\hline Previous CABG & 9 out of $131 / 7 \% /$ & 0 out of 21 \\
\hline$E F>40 \%$ & 114 out of $131 / 87 \% /$ & 20 out of $21 / 95 \% /$ \\
\hline$E F<40 \%$ & 17 out of $131 / 13 \% /$ & 1 out of $21 / 5 \% /$ \\
\hline Heart failure III NYHA & 12 out of $131 / 9 \% /$ & 1 out of $21 / 5 \% /$ \\
\hline I stage & 7 out of $131 / 5 \% /$ & 0 out of 21 \\
\hline
\end{tabular}

Table 2: Clinical characteristics.

\begin{tabular}{|c|c|c|}
\hline & I group -131 pts & II group -21 pts \\
\hline Daibetes mellitus & 51 out of $131 / 39 \% /$ & 6 out of $21 / 29 \% /$ \\
\hline Arterial hypertension & 112 out of $131 / 85 \% /$ & 21 out of $21 / 100 \% /$ \\
\hline Obesity & 45 out of $131 / 34 \% /$ & 3 out of $21 / 14 \% /$ \\
\hline Smoking & 47 out of $131 / 36 \% /$ & 5 out of $21 / 24 \% /$ \\
\hline Dyslipidemia & 102 out of $131 / 78 \% /$ & 18 out of $21 / 88 \% /$ \\
\hline Family history & 43 out of $131 / 33 \% /$ & 7 out of $21 / 33 \% /$ \\
\hline
\end{tabular}

Table 3: Risk factors.

PCI was performed according to standard methods via a radial or femoral approach using a 6 Fr guiding catheter. Treatment with clopidogrel was started prior to the procedure. Following sheath insertion, unfractionated heparin was administered as bolus doses of 10 $000 \mathrm{U}$. Analysis of the angiographic characteristic of the treated vessels shows that the target vessel was LAD in both groups (56\% in group I and $48 \%$ in group II), followed by Cx in group I (28\%) and by RCA (33\%) in group II (Figure 2). There were no left main artery angioplasty. Regarding the morphological pattern prevailed long diffuse lesions in both groups. In group I more occlusions were treated. The culprit lesion ranged from $70 \%$ to $100 \%$ diameter stenosis by quantative coronary angiography. The mean lesion length was $28 \mathrm{~mm}$ in both groups. Predilatation was done in $85 \%$ of the cases in both groups. As per the standard protocol high pressure postdilatation was performed in both groups. Only 2 patients from the first group were with implanted 2.75 $\mathrm{mm}$ stents. DES diameter varied from 3.00 to $4.00 \mathrm{~mm}$ for all of the other patients.

\section{Results}

Patients were followed up for early and late complications. Clinical condition, lab results, ECG, EchoCG of all of the patients was verified after the procedure. It was observed improvement in clinical status, ejection fraction, and physical capacity after DES placement for severe in-stent restenosis.

A few complications were registered. Acute mild complications were observed in 4 patients (from the first group) $-2.6 \%$ (Table 4 ). There were no acute serious complications (MI, emergency CABG, death) registered. No acute stent thrombosis was registered.

Long - term all the patients were followed up for 24 months ( \pm 6 months) for reversed angina, MI, emergency CABG, death, repeat revascularization, LV function assessment (Figure 3). 42 patients (28\%) were assessed by conventional coronary angiography because of recurrent angina pectoris. $9(6.8 \%)$ of the examinations revealed significant in-stent proliferation, as all of them were with implanted DES from the first generation. The others - showed patent stents, with

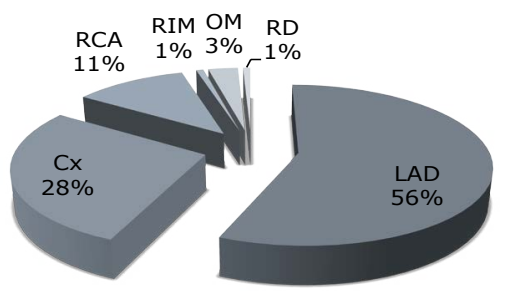

\section{I group}
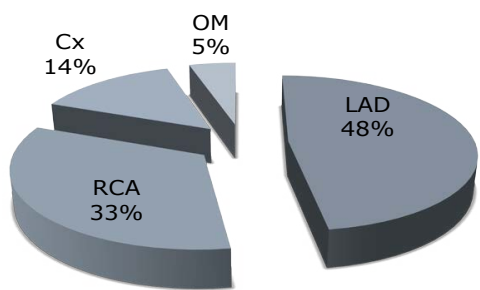

\section{II group}

Figure 2: Angiographic characteristics - treated vessels.

\begin{tabular}{|c|c|c|}
\hline Acute complications & I group - 131pts & II group - 21pts \\
\hline Vessel dissection & 1 out of $131 / 0.8 \% /$ & 0 out of 21 \\
\hline $\begin{array}{c}\text { Local hematoma, no indications } \\
\text { for hemotransfusion }\end{array}$ & 2 out of $131 / 1.5 \% /$ & 0 out of 21 \\
\hline $\begin{array}{c}\text { Local hematoma, indications for } \\
\text { hemotransfusion }\end{array}$ & 1 out of $131 / 0.8 \% /$ & 0 out of 21 \\
\hline
\end{tabular}

Table 4: Acute complications - first $48 \mathrm{~h}$ after the procedure.

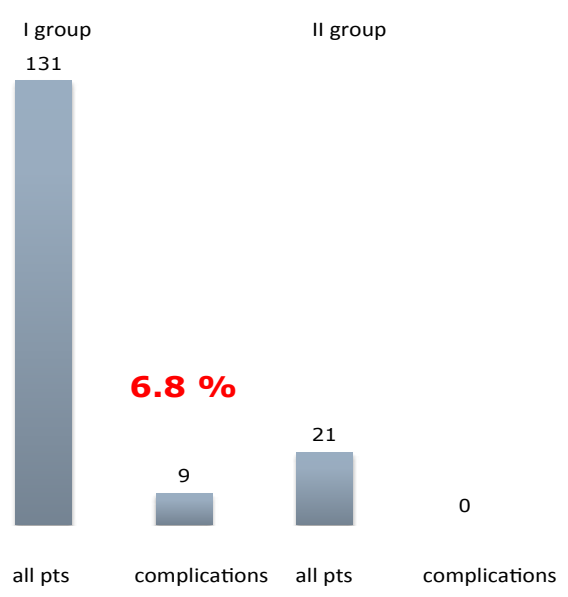

Figure 3: Follow-up and complications $-24 \pm 6$ months 
no significant proliferation. No severe complications were registered in either group.

Subanalysis of these 9 patients marked that the length ot treated segment was $>27$ Mм. 8 of them were with implanted paclitaxel-eluting stent, 1 patient - with implanted tacrolimus- eluting stent.

In 5 (out of 9) of the patients the angiography revealed in-stent occlusion, and in 4 (out of 9) - in-stent restenosis. From the 5 patients with in-stent occlusion 3 were referred for CABG. The other 2 (out of 5) were recommended for medical treatment because of low class angina and good collateral circulation. Two (out of 4) from the patients with ISR were treated with balloon angioplasty with drug- eluting balloon. The other 2 patients with ISR were referred for CABG.

\section{Discussion}

DES implantation is an alternative method in treating ISR of BMS with low rate of restenosis and late thrombosis [8]. SES do not show any difference concerning the rate of ISR and stent thrombosis when compared with second generation DES in our study. First generation PES have higher rate of ISR and stent thrombosis compared to II generation DES, pointing Taxus-Liberte analogs. The length of the stented segment shows correlations with the rate of the ISR. Our results demonstrate correlation to the latest interventional randomized controlled trials and studies concerning the use of first and second generation DES in treating ISR [9-12]. With the development of the new DES technologies there are a lot of comparisons and probably new conclusions to be made. Dedicated studies focused on the results of coronary surgery for patients with ISR remain very limited. Some investigators suggest that saphenous vein grafts have an unacceptably high incidence of failure among these patients and the use of arterial conduits should be considered to improve long-term results [13].

\section{Conclusion}

ISR remains an unresolved issue after BMS implantation especially when used in complex lesions. Implementation of DES for treatment of in-stent restenosis is a leading method, because of its reliability and safety with a very low percentage of complications and significantly reduced clinical and angiographic restenosis rates in selected patients.

\section{Limitations}

Only patients with clinical data of restenosis were checked; small group of patients were assessed by conventional coronary angiography; no IVUS controlled angiography was made to assess the grade of neointimal proliferation.

\section{References}

1. Hoffmann R, Mintz GS (2000) Coronary in-stent restenosis predictors, treatment and prevention. Eur Heart J 21: 1739-1749.

2. Moses JW, Leon MB, Popma JJ, Fitzgerald PJ, Holmes DR, et al. (2003) Sirolimus-Eluting Stents versus Standard Stents in Patients with Stenosus in a Native Coronary Artery. N Engl J Med 349(14): 1315-1323.

3. Solinas E, Dangas G, Kirtane AJ, Lansky AJ, Franklin-Bond T, et al. (2008) Angiographic patterns of drug-eluting stent restenosis and one-year outcomes after treatment with repeated percutaneous coronary intervention. Am J Cardiol 102: $311-315$

4. Steinberg DH, Gaglia MA Jr, Pinto Slottow TL, , Roy P, Bonello L, et al. (2009) Outcome differences with the use of drug-eluting stents for the treatment of instent restenosis of bare-metal stents versus drug-eluting stents. Am J Cardiol 103: 491-495.

5. Chen MS, John JM, Chew DP, Lee DS, Ellis SG, et al. (2006) Bare-metal stent restenosis is not a benign clinical entity. Am Heart J 151: 1260-1264.

6. Dangas GD, Claessen BE, Caixeta A, Sanidas EA, Mintz GS, et al. (2010) Instent restenosis in the drug-eluting stent era. J Am Coll Cardiol 56: 1897-1907.

7. Yamashita K, Ochiai M, Yakushiji T, Ebara S, Okabe T, et al. (2012) Repeat Drug-Eluting Stent Implantation for In-Stent Restenosis: First- or SecondGeneration Stent. J Invasive Cardiol 24(11): 574-578.

8. Dibra A, Kastrati A, Alfonso F, Seifarth M, Vizcayno M, et al. (2007) Effectivness of Drug-Eluting Stents in Patients With Bare-Metal In-Stent Restenosis: metaanalysis of randomized trials. J Am Coll Cardiol 49: 616-623.

9. Stone GW, Ellis SG, Cox DA, Hermiller J, O'Shaughnessy C, et al. (2004) A Polymer-Based Paclitaxel-Eluting Stent in Patients with Coronary Artery Disease. N Engl J Med 350(3): 221-331.

10. Schomig A, Dibra A, Windecker S, Mehilli J, Suarez de Lezo J, et al. (2007) A meta-analysis of 16 randomized trials of sirolimus-eluting stents versus paclitaxel-eluting stents I payients with coronary artery disease. J Am Coll Cardiol 50(14): 1381-1385.

11. Schuhlen H, Kastrati A, Mehilli J, Hausleiter J, Pache J, et al. (2004) Restenosis detected by routine angiographic follow-up and late mortality after coronary stent placement. Am Heart J 147: 317-322.

12. Park CB, Hong MK, Kim YH, Park DW, Han KH, et al. (2007) Comparison of angiographic patterns of in-stent restenosis between sirolimus- and paclitaxeleluting stent. Int J Cardiol 120: 387-390.

13. Alfonso F, Byrne RA, Rivero F, Kastrati A (2014) Current Treatment of In-Stent Restenosis. J Am Coll Cardiol 1097: 01354-0. 